\title{
Learning Styles and Their Relationship with Self-Esteem and Self-Efficacy among Nursing Students in Qazvin
}

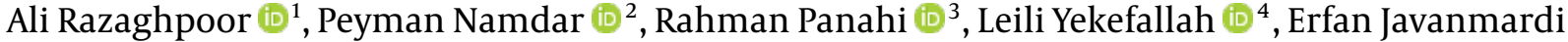 \\ (iD) ${ }^{5}$ and Leila Dehghankar (iD) ${ }^{4}{ }^{*}$ \\ ${ }^{1}$ Student Research Committee, School of Nursing \& Midwifery, Qazvin University of Medical Sciences, Qazvin, Iran \\ ${ }^{2}$ Emergency Medicine Specialist, Department of Emergency Medicine, Metabolic Disease Research Center, Qazvin University of Medical Science, Qazvin, Iran \\ ${ }^{3}$ School of Medical Sciences, Tarbiat Modares University, Tehran, Iran \\ ${ }^{4}$ Department of Nursing, Social Determinants of Health Research Center, Research Institute for Prevention of Non-communicable Diseases, School of Nursing \& Midwifery, \\ Qazvin University of Medical Sciences, Qazvin, Iran \\ ${ }^{5}$ Clinical Research Development Center, Persian Gulf Martyrs Hospital, Bushehr University of Medical Sciences, Bushehr, Iran \\ Corresponding author: Department of Nursing, Social Determinants of Health Research Center, Research Institute for Prevention of Non-communicable Diseases, School of \\ Nursing \& Midwifery, Qazvin University of Medical Sciences, Qazvin, Iran. Email: dehghan247@gmail.com
}

Received 2020 November 21; Revised 2021 February 21; Accepted 2021 February 22.

\begin{abstract}
Background: Learning styles, as individual characteristics, form and evolve as we grow older, which in turn may improve the students' educational outcomes. Identifying factors that contribute to learning styles helps us further to better achieve this goal.

Objectives: The present study aimed to, firstly, determine learning styles and, secondly, investigating their relationship with selfesteem and self-efficacy.

Methods: In this cross-sectional study, 150 nursing students were selected through a convenience sampling method. Data were collected using VARK standard questionnaire, Rosenberg self-esteem scale, and Sherer self-efficacy scale. Data were analyzed using SPSS v22 by descriptive and analytical tests.

Results: The mean age of participating students was $21.04 \pm 3.43$ years. Overall, $83.2 \%$ of them preferred one learning style. The most common preferred style was "auditory style". Mean scores of self-esteem and self-efficacy were $21.25 \pm 5.07$ and $62.66 \pm 7.31$, respectively. No significant relationship was observed between students' self-esteem and self-efficacy with their learning styles $(\mathrm{P}>$ $0.05)$.
\end{abstract}

Conclusions: Determining students' preferences for learning style is the first step to improve their educational outcomes.

Keywords: Learning, Self-Esteem, Self-Efficacy, Nursing, Education

\section{Background}

Standards of the nursing profession are constantly evolving as new evidence arise. Hence, those who teach nursing students should be at the edge of current knowledge (1). However, nursing students differ in terms of skills, abilities, experiences, levels of preparation, as well as their preferences, which these differences have brought challenges for their instructors (2). Previous studies mentioned several factors that contribute to these differences in learning, one of the most important of which is "learning styles" (3).

According to concepts and definitions of learning styles, learning has different cognitive, affective, and behavioral dimensions and is based on observation, interaction, and responsiveness $(4,5)$. Furthermore, individual characteristics such as age, gender, personality, race, and environmental factors also influence the learning abilities
(5). Therefore, educational researchers believe individuals use different learning styles that are fitted to their individual differences (6).

Several models of learning styles have been introduced in previous studies. One of these models is the "VARK learning styles model", first introduced by Fleming in $1995(4,5)$. He categorized students into four categories based on their learning styles as follows: 1-Visual learners who can learn information through the interpretation of graphs, charts, and images; 2- Aural learners prefer to learn information through discussion and listening; 3- Reading and writing learners focus on learning through elaborating notes, and 4- Kinesthetic learners prefer to learn through performing various (7). The advantage of this model is focusing on the performance of individuals in different situations (5, 8 ). Thus, the VARK model provides a good learning environment for students and encourages them to better learn 
their lessons (5).

Self-esteem, as one of the individuals' personality traits, refers to the perception the individual possesses of his/her self-worth $(9,10)$. For students, self-esteem is valuable in two aspects: 1- Effective communication between teachers and students; and 2- Creating a dynamic, positive, and productive learning cycle by students through expressing their emotions and communicating well with their teachers (11). Therefore, given the importance of selfesteem in teaching and learning, and the fact that clinical decision making and communicating with colleagues and patients are among the essential skills that nursing students must learn throughout their educations, identifying the factors related to self-esteem and how to promote it are important $(10,11)$.

Another effective motivating factor that influences individuals' learning styles is self-efficacy. Since most students are rapidly entering the field, increasing their level of self-efficacy is key (9). Numerous studies reported that family and social environment not only play an important role in nurturing the individuals' talents and health but also promote their belief in self-efficacy $(12,13)$.

Self-efficacy is also a major contributor to individuals' learning styles (14). Sherer (1982) defined self-efficacy as the belief that one can successfully perform a behavior (15). According to the literature, self-efficacy is an appropriate criterion for predicting students' academic performance (16). Since most nursing students are rapidly entering the field, increasing their level of self-efficacy can be very beneficial. The feeling of "I can do it" gives the students a sense of independence and confidence and increases their dominance (14).

\section{Objectives}

The economic, social, political, and cultural development nations depends on human resources, particularly educated professionals. Hence, identifying factors that affect students' learning, particularly their learning styles, level of self-esteem, and level of self-efficacy, is of crucial importance, particularly for developing a desirable learning cycle. In this regard, due to the importance of this issue and the lack of sufficient studies in this regard, the current study intended to investigate learning styles and their relationship with self-esteem and self-efficacy in a sample of nursing students.

\section{Methods}

This cross-sectional study was conducted on junior and senior undergraduate nursing students who were studying at Qazvin University of Medical Sciences in 2019-2020.
Participants were selected using the convenience sampling technique after evaluating against inclusion criteria, which were as follows: Being either a junior or senior undergraduate nursing student and willingness to participate in the present study. The exclusion criteria included having a history of mental health problems (either themselves or their families), suffering from social anxiety, consuming psychiatric drugs, and having physical illnesses. The sample size was calculated as 211 subjects, based on the study by Gheibi et al. (2012) (14), with a Type I error of 0.05 $(\alpha)$ and $\mathrm{d}=1.64$ using the sample-size formula. Sixty-one questionnaires were excluded due to incomplete information.

Data were collected using a questionnaire that composed four parts. The first part was a checklist for students' demographic variables, including age, sex, marital status, semester, employment status, residence status, family monthly income, and their GPA in the previous semester. The second part was the VARK Standard Questionnaire. This questionnaire consists of 16 items, each with 4 possible options. Each option represents one category of the learning style, as mentioned earlier. A higher score in each type of learning style represents the learning style for that respondent. The validity and reliability of the Persian version of this questionnaire are evaluated and confirmed in previous studies (17-19). Javadinia (2013) (18) reported reliability of 0.80 using the test-retest method. The third part was the Rosenberg self-esteem scale (RSES). This scale contains 10 items that are scored on a four-point Likert scale, ranging from strongly disagree (0) to strongly agree (3). The total score ranges from zero to 30 , with a score above 25 shows high self-esteem, between 15 and 25 is in the normal range, and below 15 suggests low self-esteem. The validity and reliability of the Persian version of this scale are reported as desirable (20). The last part of our 4-part questionnaire was Sherer self-efficacy scale, which contains 17 items. Answers are based on a 5-option Likert scale from strongly agree (1) to strongly disagree (5). Thus, the highest and lowest scores on this scale are 85 and 17, respectively. Scores below 34 show poor self-efficacy, between 35 and 51 indicate average self-efficacy, between 52 and 64 show good self-efficacy, and above 65 suggests very good self-efficacy (21). The validity and reliability of the Persian version of this scale are confirmed by Asgharnejad et al. (2006) (22).

\subsection{Data Analysis}

Data were analyzed using SPSS v22 by descriptive statistics (mean, standard deviation, and frequency table) for descriptive data (quantitative/qualitative). The KolmogorovSmirnov test was applied to test for a normal distribution. Analytical data were analyzed using Mann-Whitney, Kruskal-Wallis, and one-way ANOVA tests. Statistical significance was considered when P-value $<0.05$. 


\section{Results}

In total, 150 students participated in the present study. Data of 14 students were not included in the analysis due to the incompleteness of their questionnaires. The mean age of participants was $21.04 \pm 3.43$ years, and their GPA in the previous semester was $16.52 \pm 1.47$. Other information on students' demographic variables are provided in Table 1.

Based on the findings, $83.2 \%(n=113)$ of students preferred a single style of information presentation (either visual, auditory, reading/writing, or kinesthetic), 14.7\% (n $=20)$ preferred two styles, and only $2.1 \%(n=3)$ preferred three styles. Figure 1 presents the different ways in which students preferred to receive information based on the VARK model (Figure 1). According to this figure, the most preferred learning style among single-style students was the "auditory" style. Also, among bimodal students, the combination of the two styles of "auditory and reading/writing" accounted for the most.

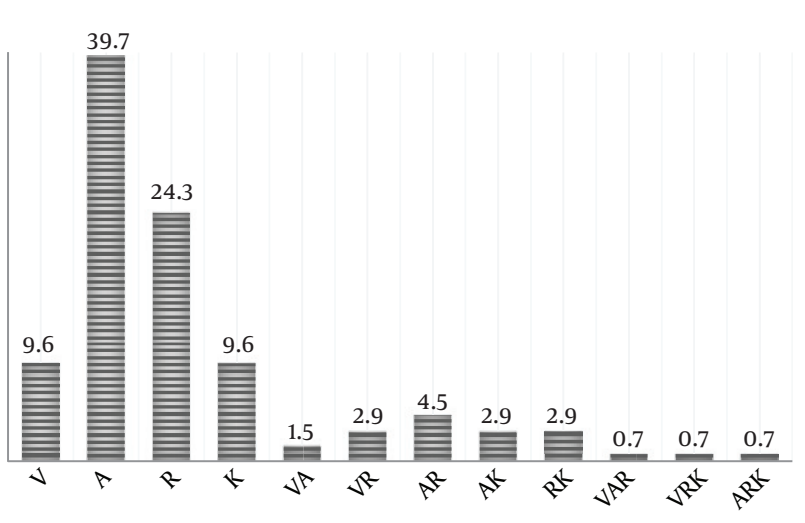

Figure 1. Comparison of VARK subcategories among nursing students

The results of the Kruskal-Wallis test showed a significant relationship between students' age $(\mathrm{P}=0.024)$, marital status $(\mathrm{P}=0.034)$, and employment status $(\mathrm{P}=0.035)$ with VARK learning styles model (Table 1 ).

The mean total score of self-esteem was $21.25 \pm 5.07$. In total, 9.6\% ( $\mathrm{n}=13)$ of students had low self-esteem, $72.0 \%$ ( $\mathrm{n}$ $=98)$ had average self-esteem, and $18.4 \%(n=25)$ had high self-esteem.

The results of the one-way ANOVA test also showed no significant relationship between students' self-esteem and their learning styles $(\mathrm{P}=0.751)$ (Table 2$)$.

The mean total score of self-efficacy was $62.66 \pm 7.31$. In total, 8.1\% $(n=11)$ of students had average self-efficacy, $73.5 \%$ $(n=100)$ had good self-efficacy, and $18.4 \%(n=25)$ had very good self-efficacy.

The results of the one-way ANOVA test also showed no significant relationship between students' self-efficacy and their learning styles $(\mathrm{P}=0.728)$ (Table 2 ).

\section{Discussion}

This study was designed and conducted to investigate learning styles and their relationship with self-esteem and self-efficacy among nursing students.

The majority of nursing students preferred one learning style to a combination of several learning styles, and the most preferred style was the "auditory". To compare the results of the present study, we can mention the study by Mehdipour et al. (2018), which reported that the majority of students preferred one learning style, and the most preferred style among them was the auditory one as well (15). These results are in line with the findings of the present study. Espinoza-Poves et al. (2019) investigated the learning styles of a group of students studying at business schools. The results of this study are consistent with the present study in terms of the students' preference for a single style but different in terms of the most preferred style (23). This difference can be attributed to the study context and educational conditions of participants between these two studies. Several studies, including those conducted by Rezigalla and Ahmed (2019), Zamani and Kaboodi (2015), Zeighami et al. (2013), and Javadinia et al. (2012), also reported the auditory style as the most preferred style among medical students $(16,18,24,25)$. Overall, as lectures provided by instructors are the dominant teaching method in Iran and, even, sometimes the instructor is the sole speaker, the auditory style was expected to be the preferred style.

However, it seems that a series of changes in the education system is necessary to facilitate achieving these goals among university students, especially those studying medicine, because they receive most of their education in the hospital environment and at the patient's bedside. To meet this end, it seems necessary for them to consider a combination of several learning styles rather than one single style (26).

According to the findings, among the demographic variables, only age, marital status, and employment status had a significant relationship with the learning styles of students. In this regard, Espinoza-Poves et al. (2019) and Alkooheji and Al-Hattami (2018) also reported a significant relationship between the participants' age and their learning style $(23,27)$. These results are consistent with the findings of the present study. Based on our literature review, limited studies have investigated the relationship between learning styles and participants' marital status and employment status. Regarding the relationship between learning styles and marital status, Zeighami et al. (2013) revealed a significant relationship between nursing and midwifery students' marital status and reading/writing style (25), which in general is consistent with the finding of the present study. Regarding the relationship between learning styles and employment status, in one study, Fitkov- 


\begin{tabular}{|c|c|c|c|c|}
\hline \multirow[t]{2}{*}{ Demographic Variables } & \multirow[t]{2}{*}{ Frequency (\%) } & \multicolumn{2}{|c|}{ Learning Styles } & \multirow[t]{2}{*}{ P-Value } \\
\hline & & Mean Ranks & Median (Interquartile Range) & \\
\hline Sex & & & & 0.467 \\
\hline Female & $82(60.3)$ & 66.59 & $2.00(1.25)$ & \\
\hline Male & $54(39.7)$ & 71.41 & $3.00(2.00)$ & \\
\hline Age (y) & & & & $0.024^{\mathrm{a}}$ \\
\hline$<20$ & $41(30.1)$ & 62.60 & $2.00(1.50)$ & \\
\hline $20-30$ & $90(66.2)$ & 68.81 & $2.00(3.00)$ & \\
\hline$>30$ & $5(3.7)$ & 111.40 & $8.00(8.50)$ & \\
\hline Marital status & & & & $0.034^{\mathrm{a}}$ \\
\hline Single & $127(93.4)$ & 66.67 & $2.00(2.00)$ & \\
\hline Married & $9(6.6)$ & 94.39 & $3.00(6.00)$ & \\
\hline Semester & & & & 0.154 \\
\hline 1st & $48(35.3)$ & 60.84 & $2.00(1.00)$ & \\
\hline 2nd & $48(35.3)$ & 78.16 & $3.00(3.50)$ & \\
\hline 7th & $15(11.0)$ & 65.70 & $2.00(2.00)$ & \\
\hline 8th & $25(18.4)$ & 66.34 & $2.00(1.50)$ & \\
\hline Employment status & & & & $0.035^{\mathrm{a}}$ \\
\hline Yes & $24(17.6)$ & 83.25 & $3.00(5.50)$ & \\
\hline No & $112(82.4)$ & 65.34 & $2.00(1.00)$ & \\
\hline Residence & & & & 0.402 \\
\hline City & $58(43.6)$ & 64.37 & $2.00(1.25)$ & \\
\hline Suburbs & $25(18.8)$ & 71.94 & $3.00(2.50)$ & \\
\hline Village & $1(0.8)$ & 121.50 & & \\
\hline Dormitory & $49(36.8)$ & 66.48 & $2.00(1.00)$ & \\
\hline Families' monthly income (M) & & & & 0.060 \\
\hline$<1$ & $12(9.3)$ & 61.17 & $2.50(1.00)$ & \\
\hline $1-2$ & $40(31.0)$ & 66.50 & $3.00(2.00)$ & \\
\hline $2-3$ & $35(27.1)$ & 76.81 & $3.00(4.00)$ & \\
\hline$>3$ & $42(32.6)$ & 54.82 & $2.00(1.00)$ & \\
\hline
\end{tabular}

${ }^{\text {a }}$ Significance level was considered less than 0.05.

Norris and Yeghiazarian (2013) investigated the relationship between learning styles and some demographic characteristics of postgraduate general business management students. The results of this study also showed a significant relationship between students' learning styles and their employment status. In other words, the students with some work experience did not have a strong learning preference and utilized a combination of several learning styles to solve their problems (28). In another study, Espinoza-Poves et al. (2019) reported no significant relationship between students' learning styles and their employment status (23), which is not in line with the findings of the present study. The reason for this difference may be related to the student's field of study in the two studies.

The results of the present study also showed no significant relationship between student's self-esteem and their learning styles. Our literature review did not reveal a similar study on medical students. However, Algharaibeh (2019) conducted a study entitled "Interaction between self-esteem and learning styles on academic achievement among secondary school students" and reported a positive relationship between self-esteem and learning style (29). This result contradicted the finding of the present study, which can be attributed to the differences in the samples 


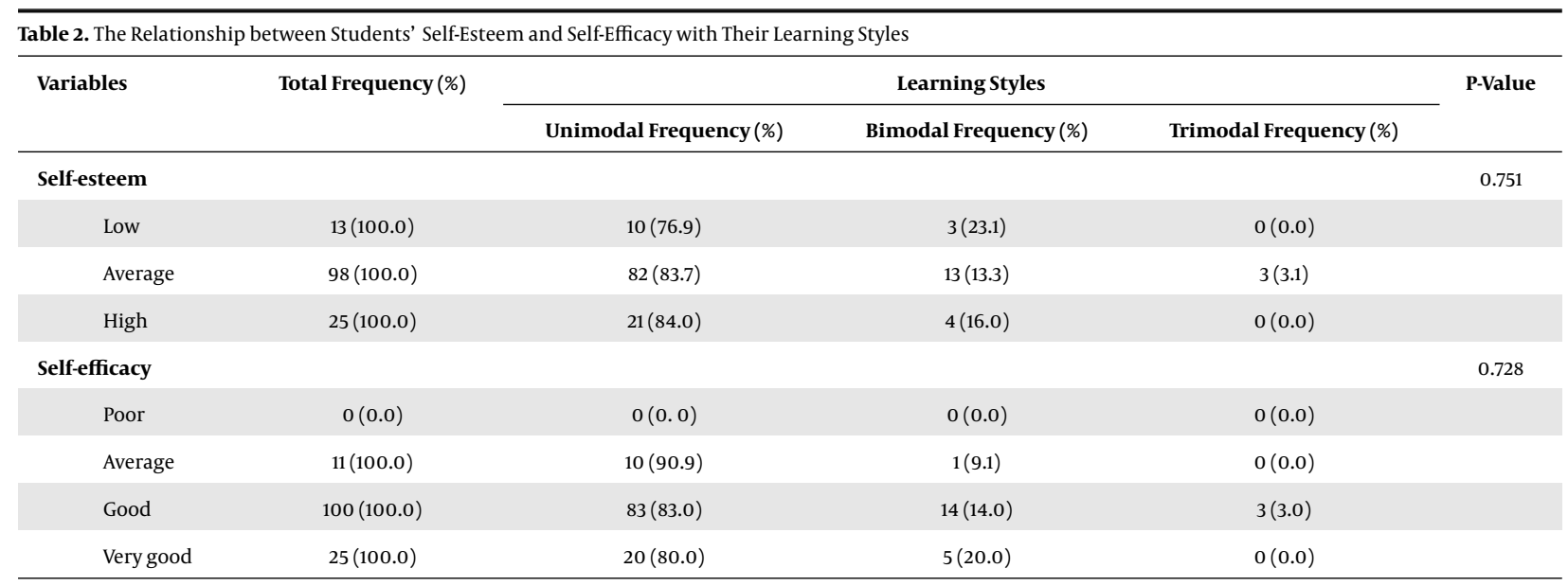

and the questionnaires used in the two studies. However, due to the lack of sufficient studies on the relationship between learning styles and self-esteem, further studies are recommended in this regard.

The results of the present study also showed no significant relationship between student's self-efficacy and their learning styles. One of the possible reasons for this finding is that self-efficacy may be related to various factors, only one of which is learning style (14). Limited studies are available in this regard among students, especially medical students. Jordan, Heilat et al. (2010) showed no significant relationship between student's self-efficacy and their learning style (30), which this result is in line with the finding of the present study. In another study, which its findings are not in line with the findings of the present study, Arbabisarjou et al. (2016) examined the relationship between learning styles and self-efficacy among medical students of Zahedan University and showed a significant relationship between student's self-efficacy and their learning (31). The reason for this difference may be related to the different questionnaires used in these two studies. In the present study, researchers used Sherer self-efficacy scale, while Arbabisarjou et al. used the self-efficacy questionnaire (designed by Pintrich et al.). However, due to the lack of sufficient studies on the relationship between learning styles and self-esteem, further studies are recommended in this regard.

\subsection{Limitations}

It is necessary to mention some limitations of the present study, including a small sample size and using a self-administered questionnaire.

\subsection{Conclusion}

This study identified that most of the nursing students preferred one learning style, and the most preferred one was the auditory style. Determining students' preferences for learning style is the first step to improve their educational outcomes. In addition, we found no relationship between student's self-esteem and self-efficacy with their learning style. Since nursing students receive most of their education in the hospital environment, it seems necessary to identify factors affecting their learning styles to help them and their instructors to create a desirable learning cycle. Due to the lack of similar studies, it is highly recommended to consider other affecting factors in future studies.

\section{Acknowledgments}

The authors would like to thank the research officials of Qazvin University of Medical Sciences for their support. It is also necessary to thank the participants for their cooperation.

\section{Footnotes}

Authors' Contribution: Conception and design were done by AR, LD; collection and assembly of data were done LD, and LY; data analysis and interpretation were done by RP, EJ; manuscript writing was done by AR, LD, RP, and PN. The final approval of the manuscript was done by all authors.

\section{Conflict of Interests: None.}

Ethical Approval: The study protocol was approved in terms of ethical considerations by the Committee for Ethics of the Qazvin University of Medical Sciences (IR.QUMS.REC.1397.396)

Funding/Support: The authors received financial support for the research of Qazvin University of Medical Sciences. 
Informed Consent: Each participant completed and signed the informed consent form to participate in the study.

\section{References}

1. Fleming S, McKee G, Huntley-Moore S. Undergraduate nursing students' learning styles: A longitudinal study. Nurse Educ Today. 2011;31(5):444-9. doi: 10.1016/j.nedt.2010.08.005. [PubMed: 20863600].

2. Rassool GH, Rawaf S. Learning style preferences of undergraduate nursing students. Nurs Stand. 2007;21(32):35-41. doi: 10.7748/ns2007.04.21.32.35.c4495. [PubMed: 17479786]

3. Kara S. Learning styles and teaching styles: A case study in foreign language classroom. Conference of the International Journal of Arts and Sciences. Freiburg, Germany; 2009. p. 77-82.

4. Zapalska AM, Dabb H. Learning Styles. J Teach Int Bus. 2002;13(3-4):7797. doi: 10.1300/J066v13n03_06.

5. Othman N, Amiruddin MH. Different perspectives of learning styles from VARK model. Procedia Soc Behav Sci. 2010;7:652-60. doi: 10.1016/j.sbspro.2010.10.088.

6. Zeraati A, Hajian H, Shojaian R. Learning styles of medical and midwifery students in Mashhad University of Medical Sciences.J Med Edu. 2008;12(1-2):17-22.

7. Fleming ND. VARK visual, aural/auditory, read/write, kinesthetic. New Zealand: Bonwell Green Mountain Falls. 2006

8. Klement M. How do my students study? An analysis of students' of educational disciplines favorite learning styles according to VARK classification. Procedia Soc Behav Sci. 2014;132:384-90. doi: 10.1016/j.sbspro.2014.04.326.

9. Cha NH, Sok SR. Depression, self-esteem and anger expression patterns of Korean nursing students. Int Nurs Rev. 2014;61(1):109-15. doi: 10.1111/inr.12076. [PubMed: 24308513].

10. Valizadeh L, Zamanzadeh V, Gargari RB, Ghahramanian A, Tabrizi FJ, Keogh B. Pressure and protective factors influencing nursing students' self-esteem: A content analysis study. Nurse Educ Today. 2016;36:468-72. doi: 10.1016/j.nedt.2015.10.019. [PubMed: 26586259].

11. Shafian H, Azizzadeh-Forouzi M, Haghdoost AA, Garrusi B. [Prediction of learning styles using students selfesteem]. Stride dev med educ. 2017;13(5):451-9. Persian.

12. Bandura A. Self-efficacy: The exercise of control. New York, USA: WH Freeman;1997.

13. Hampton NZ, Mason E. Learning disabilities, gender, sources of efficacy, self-efficacy beliefs, and academic achievement in high school students. J Sch Psychol. 2003;41(2):101-12. doi: 10.1016/s00224405(03)00028-1.

14. Gheibi M, Arefi M, Danesh E. [Relationship between learning style and self-efficacy in students of academic groups]. J Appl Psychol. 2012;6(1 (21)):53-62. Persian.

15. Mehdipour M, Mortazavi H, Yazdani J, Namdari M, Moradi M. [Learning styles of dental students at Shahid Beheshti University of Medical Sciences using VARK questionnaire]. Iranian Journal of Medical Education. 2018;18:176-82. Persian.

16. Rezigalla AA, Ahmed OY. Learning style preferences among medical students in the College of Medicine, University of Bisha, Saudi Arabia
(2018). Adv Med Educ Pract. 2019;10:795-801. doi: 10.2147|AMEP.S219176. [PubMed: 31565016]. [PubMed Central: PMC6735654].

17. Jannat Alipour Z, Navvabi N, Jahanshahi M. [Evaluation of nursing students' learning styles based on VARK learning pattern in Ramsar school of nursing \& midwifery]. Biannual Journal of Medical Education Education Development Center (edc) Babol University of Medical Sciences. 2013;1(2):37-45. Persian.

18. Javadinia A, Sharifzade G, Abedini M, Khalesi M, Erfaniyan M. [Learning styles of medical students in Birjand University of medical sciences according to VARK model]. Iranian journal of medical education. 2012;11(6):584-9. Persian.

19. Peyman H, Sadeghifar J, Alizadeh M, Yaghoubi M, Mohammad Hassan Nahal M, Yamani N, et al. [Learning styles of first year nursing and midwifery students in Ilam University of Medical Sciences]. Iranian Journal of Medical Education. 2012;11(9):1350-8. Persian.

20. Rajabi G, Bohlol N. Validity and reliability of Rosenberg self-esteem scale in first year student of Shahid Chamran University. New Educ Approaches. 2006;3(2):33-48.

21. Shamsaei F, Vakili R, Rezaie AA, Salavati M, Moghimbeigi A. The association of self-efficacy with general health in patients with multiple sclerosis. Jundishapur J Chronic Dis Care. 2014;3(4). doi: 10.17795/jjcdc23367.

22. Asgharnejad T, Ahmadi Dehghotboddini M, Vali Elah F, Khodapanahi MK. [Psychometric properties of sherer's general self-efficacy scale]. J Psychol. 2006;10(3 (39)):262-74. Persian.

23. Espinoza-Poves JL, Miranda-Vílchez WA, Chafloque-Céspedes R. The Vark learning styles among university students of business schools. JEduc Psychol.2019;7(2):384-414. doi: 10.20511/pyr2019.v7n2.254.

24. Zamani N, Kaboodi A. Evaluation of the VARK model learning styles selection in medical students. J Health Res. 2017;2(2):109-15. doi: 10.18869/acadpub.hrjbaq.2.2.109.

25. Zeighami R, Jahani-Hashem $\mathrm{H}$. [Correlation between learning styles and the characteristics of nursing and midwifery students in Qazvin University of Medical Sciences using the VARK model]. J Nurs Educ. 2013;2(1):27-35. Persian.

26. Hejazi A, Taherpour M, sobhani KH, Hosseini S, Hedayati M, Barzegar A. [Evaluation of student learning styles of North Khorasan University of Medical Sciences based on VARK model]. Journal of North Khorasan University of Medical Sciences. 2015;7(1):55-62. Persian. doi: 10.29252/jnkums.7.1.55

27. Alkooheji L, Al-Hattami A. Learning style preferences among college students. Int Educ Stud. 2018;11(10):50. doi:10.5539/ies.v11n10p50.

28. Fitkov-Norris E, Yeghiazarian A. Assessing the learning style preferences postgraduate general business management students using VARK.In: Ramos I, Mesquita A, editors. Proceedings of the 12th European Conference on Research Methodology for Business and Management Studies. UK. Academic Conferences and Publishing International Ltd; 2013. p. 144-52.

29. Algharaibeh S. [Interaction between self-esteem and learning styles on academic achievement among secondary school students in Hail]. MECSJ. 2019;11:1-36. Arabic.

30. Al-zoubi AM, Heilat MQ. Effect of preferred learning styles on self ef ficacy among female students of the department of educational sciences, Princes University College Alia.J Educ Psychol. 2010;11(1):265-90. doi: $10.12785 /$ jeps/110110.

31. Arbabisarjou A, Sotoudeh M, Zare S, Shahrakipour M, Ghoreishinia Gh. Is there any relationship between student's learning styles and self-efficacy? Int J Humanit. 2016;3(1). 